\title{
Revue de Bibliothèque et Archives nationales du Québec
}

\section{Le fil de notre histoire}

Guy Berthiaume

Numéro 4, 2012

URI : https://id.erudit.org/iderudit/1012092ar

DOI : https://doi.org/10.7202/1012092ar

Aller au sommaire du numéro

Éditeur(s)

Bibliothèque et Archives nationales du Québec

ISSN

1920-0250 (imprimé)

1920-0269 (numérique)

Découvrir la revue

Citer ce document

Berthiaume, G. (2012). Le fil de notre histoire. Revue de Bibliothèque et Archives nationales du Québec, (4), 4-5. https://doi.org/10.7202/1012092ar d'utilisation que vous pouvez consulter en ligne.

https://apropos.erudit.org/fr/usagers/politique-dutilisation/ 


\section{Le fil de notre histoire}

Guy Berthiaume

Président-directeur général

Bibliothèque et Archives nationales du Québec
Il est habituel, quand on écrit l'histoire, de situer les grandes figures et de brosser un portrait tapissé de hauts faits et de dates charnières. Une telle démarche ne manque évidemment pas d'intérêt : loin de moi l'idée de remettre en cause l'importance de l'histoire politique. Mais il existe d'autres avenues pour mettre en valeur notre passé : des chemins de traverse, des passages plus obscurs, voire des passerelles ténues, qui jettent un éclairage inédit sur notre patrimoine et renouvellent la compréhension que nous en avons. Les études réunies ici illustrent de manière éloquente ce phénomène, en abordant la culture et l'histoire québécoises par leurs versants les moins fréquentés.

C'est ainsi que, pour la première fois, la Revue de Bibliothèque et Archives nationales du Québec s'ouvre à l'architecture en accueillant rien de moins que deux textes plutôt qu'un. Les auteures de ces articles, Caroline Beaudoin et Josette Michaud, nous invitent à voir d'un autre œeil ces géants familiers que sont les églises en montrant combien ces monuments sont révélateurs des communautés dont ils étaient jadis le coeur. Pour $\mathrm{M}^{\mathrm{me}}$ Beaudoin, l'analyse des plans de l'église Sainte-Marguerite-Marie de Magog permet de lever le voile sur une partie de l'histoire sociale de cette cité industrielle dont les habitants étaient pour la plupart ouvriers à l'usine de la Dominion Textile. $\mathrm{M}^{\mathrm{me}}$ Michaud procède avec finesse à l'examen des plans de l'église Saint-Patrice de Rivière-du-Loup, ce qui l'amène à remonter le fil de l'histoire du bâtiment et à retracer les intentions de ses architectes successifs.

Les choses qui nous sont les plus coutumières, étrangement, sont souvent celles sur lesquelles nous nous interrogeons le moins. L'article de Josée Vincent sur les manuels techniques de Louis-Alexandre Bélisle, ces " petits ouvrages d'apparence modeste et aux titres bien souvent fort ennuyeux », comme elle n'hésite pas 
à les qualifier, le donne bien à voir : le témoignage que nous livrent ces manuels est fascinant. De même, la contribution de Fanie St-Laurent sur le corpus pratiquement oublié du Bulletin de la Société d'étude et de conférences révèle comment la culture a été l'un des moyens privilégiés par les femmes pour accéder à l'espace public. Enfin, Dominic Hardy nous convie à revisiter les débuts de la vie démocratique au Bas-Canada par l'entremise d'une source documentaire pour le moins inusitée, la caricature, et la plume originale d'un homme d'affaires impliqué dans sa mise en marché, Louis Dulongpré. Partir de l'ordinaire et du familier, de la vie quotidienne et de ses figures discrètes, ce n'est donc pas seulement interroger l'histoire différemment, c'est aussi lui fournir une texture et une profondeur indispensables, sans lesquelles elle se figerait en une sorte de nature morte.

Marqués au coin de la discrétion, l'on retrouve les personnages dont les fonds documentaires n'ont pour ainsi dire pas gardé trace. Peut-on les exhumer de l'anonymat qui les caractérise? C'est à l'un de ces " absents de l'histoire », pour reprendre la belle expression de Michel de Certeau ${ }^{1}$, qu'Éva Guillorel consacre un article. À l'issue d'une enquête minutieuse dans les dépôts d'archives français et québécois, l'auteure est parvenue à tirer de l'ombre le parcours singulier de Pierre Collas, un jeune Berrichon n'ayant séjourné que cinq ans en Nouvelle-France, et à mettre au jour l'existence jusqu'alors méconnue de toute une catégorie de population qui n'apparaît presque jamais dans les sources manuscrites de la colonie : celle des colons malheureux qui retournent vivre dans la mère patrie après quelques années au loin.
À l'autre bout du spectre, dans le camp de ceux qui ont laissé d'abondants témoignages de leur passage et de leurs motivations, se trouvent les missionnaires jésuites, que le texte signé par Jean-François Palomino saisit d'une façon tout à fait neuve, en déplaçant les projecteurs en direction des pratiques cartographiques qu'ils mettent en œuvre et à profit dans leurs Relations. C'est dire combien un simple changement de perspective peut s'avérer porteur : des textes aussi renommés que les lettres du Nouveau Monde prennent, tout d'un coup, une couleur inattendue, de la même manière qu'un personnage apparemment « sans histoire » découvre avec lui tout un pan du grand récit
«Partir de l'ordinaire et du familier, de la vie quotidienne et de ses figures discrètes, ce n'est donc pas seulement interroger l'histoire différemment, c'est aussi lui fournir une texture et une profondeur indispensables, sans lesquelles elle se figerait en une sorte de nature morte.» historique auquel il appartient dès lors qu'on le regarde autrement. La rubrique archivistique de nos collègues Julie Roy et Hélène Fortier offre un dernier exemple de ce procédé : en plus de mettre la région de l'Estrie à l'avant-scène, leur chronique nous livre l'un des secrets les mieux gardés du fonds Alfred DesRochers, la correspondance pleine de tendresse que le poète a entretenue avec sa fille Clémence. De l'intimité d'un amour filial jusqu'aux stratégies pour convertir un continent, les fils documentaires qui tissent la trame de notre histoire auront rarement été si variés. 